\title{
Optimization of Intervening Variables in MicroEDM of SS 316L using a Genetic Algorithm and Response-Surface Methodology
}

\author{
Periyakgounder Suresh ${ }^{1, *}$ - Rajamanickam Venkatesan ${ }^{1}$ - Tamilperruvalathan Sekar ${ }^{2}$ - \\ - Natarajan Elango ${ }^{3}$ - Varatharajan Sathiyamoorthy ${ }^{4}$ \\ ${ }^{1}$ Sona College of Technology, Department of Mechanical Engineering, India \\ 2 Government College of Engineering, Department of Mechanical Engineering, India \\ ${ }^{3}$ Kolej University Linton, School of Mechanical Engineering, Malaysia \\ ${ }^{4}$ Mahendra Engineering College, Department of Mechanical Engineering, India
}

This research paper attempts to investigate the optimum values of the major intervening parameters in micro-Electric Discharge Machining (microEDM) of Stainless Steel (SS) 316L. Experiments are conducted using a 400 micrometre brass electrode. The discharge current, pulseon time and pulse-off time with three levels are selected as significant intervening parameters. The Taguchi method is initially applied to determine the optimum process parameters and the number of experiments required to model the responses. The response-surface methodology (RSM) is applied to correlate between intervening parameters, and the selected objectives to maximize the material removal rate (MRR) and to minimize the tool wear rate (TWR) in the machining of SS $316 \mathrm{~L}$. The mathematical model obtained from RSM is used as a fitness function to multi-objective optimization using a genetic algorithm (GA). The results reveal that the resulting optimal intervening parameters improve the chosen objectives significantly. The confirmation results prove that the better developed mathematical model yields deviate within $5 \%$ of the experiment.

Keywords: response-surface methodology, genetic algorithm, stainless steel 316L, Taguchi method

\section{INTRODUCTION}

Electrical discharge machining $(E D M)$ is the most widely used and most successfully applied method to machine conductive hard materials. It is a nontraditional machining process in which metal is removed by producing powerful electric spark discharge between the tool electrode and the work material. Both the work piece and the tool are submerged in a dielectric fluid and a servo-mechanism is employed to maintain the spark gap.

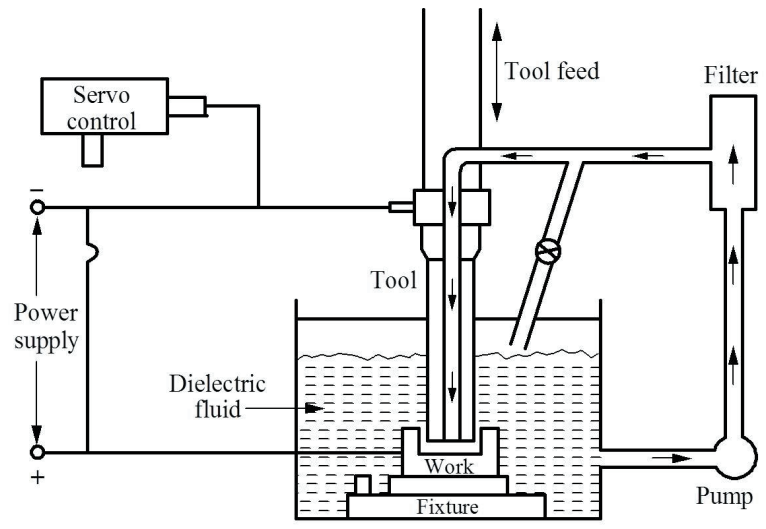

Fig. 1. Schematic layout of microEDM

A high-power spark is produced when the voltage across the gap becomes sufficiently large. Hence, the dielectric fluid breaks down and the gap is ionized. Thousands of sparks occur per second at the spark gap and make the work-piece metal melt and erode. The removed metal is carried away by the dielectric fluid circulated around it, as shown in Fig. 1 [1] and [2].

In EDM, the problem of cutting force and vibration is avoided since the tool does not contact the work piece directly. In spite of many advantages, it has some limitations, such as longer lead time, lower productivity and higher energy consumption. Therefore, recent research focuses on optimizing the process parameter to increase the productivity and the capability of the process. The experimental methods increase the cost of investigation, and performing all the experiments is not feasible, particularly when the number of parameters and their levels are high. The Taguchi method has evolved to become the most powerful way to improve the productivity of EDM [3] and [4]. It was used for experimental design to optimize the cutting parameters of the turning of E0300 alloy steel [5]. Natarajan and Arunachalam [6] applied this method and the grey relational analysis to optimize the process parameters of stainless steel grade 304 with brass electrodes $500 \mu \mathrm{m}$ in diameter. Dhanabalan et al. [7] optimized the process parameters of titanium grades in EDM. Mukherjee and Ray [8] presented a generic framework for parameter optimization in metal cutting processes for the selection of an appropriate approach. The response-surface methodology (RSM) explores the relationships between several explanatory variables and one or more response variables. It will successfully relate the input process parameters and 
output response variables [9] and [10]. It is a statistical method that uses quantitative data from experiments to determine and simultaneously solve multi-variant equations. Karthikeyan et al. [11] conducted general factorial experiments for microEDM in order to present an exhaustive study of parameters on the material removal rate (MRR) and the tool wear rate (TWR). Kung et al. [12] introduced powder-mixed EDM when machining cobalt-bonded tungsten carbide. The RSM was used to plan and analyse the experiments in terms of MRR and electrode wear ratio (EWR). They concluded that the aluminium powder mixed with dielectric fluid increases the MRR and reduces the EWR. Genetic algorithms (GA) and artificial neural networks (ANN) are popular software technologies used for the optimization of machining parameters. Samtas et al. [13] investigated the effects of cutting parameters and deep cryogenic treatment on the thrust force in the drilling of AISI 316 stainless steel. Saric et al. [14] used neural networks to predict and simulate the surface roughness of the steel, by using back-propagation neural networks, modular neural networks, and radial basis function neural networks in the process of modelling. Kao and Hocheng [15] applied grey relational analysis for optimizing the electro-polishing of 316L stainless steel with multiple performance characteristics. Lee et al. [16] studied the process of ball burnishing AISI 316L stainless steel, in which they used Taguchi techniques for the statistical design of experiments for achieving good surface finish on flat specimens. Pushpendra et al. [17] developed an artificial neural network model for the experimental values and then applied a non-dominated sorting genetic algorithm (NSGA II) to predict the MRR and surface roughness (SR) for Inconol 718. They concluded experimental results with a set of pareto-optimal solutions. Baraskar et al. [18] developed empirical models relating the surface roughness and MRR of EN8 steel with the process parameters such as pulse-on time, pulse-off time, and discharge current. They used a multi-objective optimization tool, NSGA II, to obtain the pareto-optimal set of solutions. Though much research has been done in the field of the machining of stainless steel, the optimization of machining parameters of microEDM of SS316L has not been addressed.

\section{EXPERIMENTAL DETAIL}

The stainless steel $(316 \mathrm{~L})$ considered in this research is a metal used in pharmaceuticals, marine and medical applications. It has a significant role in medical implants, including pins, screws and orthopaedic implants, such as total hip and knee replacements, due to various mechanical properties, such as high oxidation resistance, corrosive resistance and hardness. Though there are many process parameters that influence the machinability criteria of microEDM, this research dealt with three important processes: parameter-discharge current, pulse-on time Ton, and pulse-off time Toff. The Taguchi method was initially applied to determine the optimum process parameters and the number of experiments required to model response functions. RSM was then successfully applied to relate the input process parameters and the output responses of the selected material. The mathematical model obtained from RSM was then used as a fitness function for GA multi objective optimization.

A schematic of the experiment was performed in a SPARKONIX microEDM machine as shown in Fig. 2 with a brass electrode (diameter: $400 \mu \mathrm{m}$ ) and deionized water as a dielectric fluid for machining the selected 316L stainless steel work piece.

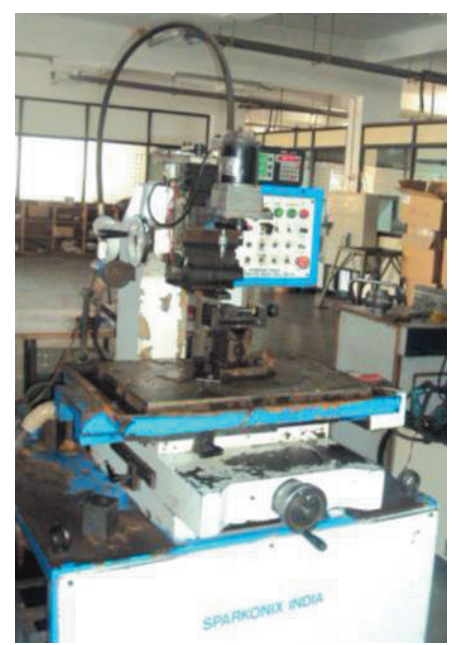

Fig. 2. Sparkonix microEDM machine

\subsection{Design of Experiment (DOE)}

The Taguchi method is a powerful approach that provides a simple, efficient and systematic approach to determine the optimum process parameters, which drastically reduces the number of experiments that are required to model response functions [7] and [8]. It is a method based on orthogonal array (OA) experiments, which provide the much-reduced variance for the experiment resulting in the optimum setting of process control parameters.

The major influencing parameters and their levels considered are listed in Table 1. The selection of the 
orthogonal array is based on the number of process parameters and their levels. In the current research, the L9 orthogonal array with three rows and nine columns is selected as given in Table 2.

The tool wear rate for each experiment are calculated as:

TWR $=\frac{\text { Initial weight of tool }- \text { Final weight of tool }}{\text { Machining time }}$.

The material removal rate for each experiment is calculated as:

MRR $=\frac{\text { Weight before machining }- \text { Weight after machining }}{\text { Machining time }}$.

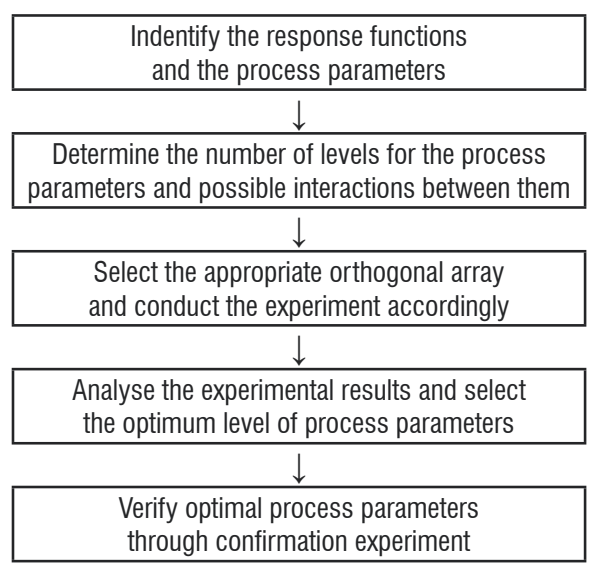

Fig. 3. Steps involved in the Taguchi method

Table 1. Machining parameters and their levels

\begin{tabular}{lccc}
\hline Parameters & Level 1 & Level 2 & Level 3 \\
\hline Discharge current $[\mathrm{A}]$ & 6 & 9 & 12 \\
\hline Pulse-on time $[\mu \mathrm{s}]$ & 3 & 6 & 9 \\
\hline Pulse-off time $[\mu \mathrm{s}]$ & 3 & 6 & 9 \\
\hline
\end{tabular}

\subsection{Response-Surface Methodology (RSM)}

In most RSM problems, the form of the relationship between the response and the independent variables is unknown. Thus, the first step in RSM is to find a suitable approximation for the actual relationship between the response and the process parameters. The quantitative form of relationship between the desired response and independent input variables can be represented as:

$$
y=f\left(x_{1}, x_{2}, x_{3}, \ldots, x_{n}\right)+\varepsilon,
$$

where, $y$ is the desired response, $f$ is the response function (or response-surface), $x_{1}, x_{2}, x_{3}, \ldots, x_{n}$ are the independent input variables, and is the fitting error.

The appearance of the response function looks like a surface curve while plotting the expected response of $f$. The identification of suitable approximation for $f$ will determine whether or not the application of RSM is successful. The necessary data for building the response model are generally collected from the design of experiments.

In the current research, the experimental data were fitted into a two-factor interaction (2FI) regression model. The general form of 2FI model is:

$$
f=\beta_{0}+\sum_{i=1}^{n} \beta_{i} x_{i}+\sum_{i<j}^{n} \beta_{i j} x_{i} x_{j}+\varepsilon
$$

where, $f$ is the desired response, $\beta_{i}$ represents the linear effect of $x_{i}, \beta_{i j}$, represents the quadratic effect of $x_{i}$. They are cross-product terms that reveal a linearby-linear interaction between $x_{i}$ and $y_{i} . \varepsilon$ is a statistical error term.

Design Expert R7.0 software was used to obtain regression models for two responses separately.

\begin{tabular}{|c|c|c|c|c|c|c|}
\hline \multirow[b]{2}{*}{ Experiment } & \multicolumn{3}{|c|}{ Machining Parameter Level } & \multirow[b]{2}{*}{$\begin{array}{l}\text { Total machining } \\
\quad \text { time [s] }\end{array}$} & \multirow{2}{*}{$\begin{array}{l}\text { TWR } \\
{[\mathrm{mg} / \mathrm{s}]}\end{array}$} & \multirow{2}{*}{$\begin{array}{l}\text { MRR } \\
{[\mathrm{mg} / \mathrm{s}]}\end{array}$} \\
\hline & $\begin{array}{l}\text { Discharge current } \\
{[\mathrm{A}]}\end{array}$ & $\begin{array}{c}\text { Pulse-on time } \\
{[\mu \mathrm{s}]}\end{array}$ & $\begin{array}{c}\text { Pulse-off time } \\
{[\mu \mathrm{s}]}\end{array}$ & & & \\
\hline 1 & 6 & 3 & 3 & 306.45 & 0.02576 & 0.64545 \\
\hline 2 & 6 & 6 & 6 & 140.30 & 0.07466 & 0.94500 \\
\hline 3 & 6 & 9 & 9 & 108.09 & 0.08077 & 1.35233 \\
\hline 4 & 9 & 3 & 6 & 109.84 & 0.09538 & 1.36724 \\
\hline 5 & 9 & 6 & 9 & 76.30 & 0.17163 & 1.86400 \\
\hline 6 & 9 & 9 & 3 & 74.20 & 0.25884 & 1.37924 \\
\hline 7 & 12 & 3 & 9 & 51.34 & 0.25506 & 2.58245 \\
\hline 8 & 12 & 6 & 3 & 67.81 & 0.32185 & 2.06539 \\
\hline 9 & 12 & 9 & 6 & 42.54 & 0.26678 & 3.20636 \\
\hline
\end{tabular}

Table 2. Experimental design using L9 orthogonal array 
The mathematical model correlating MRR with the process control parameters is obtained as:

$$
\begin{aligned}
\text { MRR } & =0.66885+0.076855 x_{1}-0.15883 x_{3}- \\
& -0.31122 x_{1}+\left(0.011663 x_{1} x_{2}\right)+ \\
& +\left(0.028113 x_{1} x_{3}\right)+\left(0.028438 x_{2} x_{3}\right) .
\end{aligned}
$$

The mathematical model correlating TWR with the process control parameters is obtained as:

$$
\begin{aligned}
\mathrm{TWR}= & -0.384951429+0.053079841 x_{1}+ \\
& +0.05632381 x_{1}-0.003937302 x_{3}- \\
& -\left(0.003577937 x_{1} x_{2}\right)+\left(0.000419524 x_{1} x_{3}\right)- \\
& -\left(0.001784127 x_{2} x_{3}\right),
\end{aligned}
$$

where $x_{1}$ is discharge current, $x_{2}$ pulse-on time, and $x_{3}$ pulse-off time.

Figs. 4 and 5 show the linear correlation between the predicted values and the actual values of MRR and TWR. In the ANOVA test, if $p$ value is less than 0.05 , the developed model is significant; otherwise, it is insignificant. The coefficient of determination $\left(R^{2}\right)$ and Adj. $R^{2}$ from the ANOVA test in MRR are observed to be 0.9833 and 0.9331 , respectively. Similarly, from the ANOVA test, in TWR, $R^{2}=0.9656$ and Adj. $R^{2}=0.8622$, which proves that the developed model is statistically considerable.

\subsection{The Effect of Discharge Current on MRR and TWR with Various Pulse-on Time}

Experiments were conducted on the chosen stainless steel $316 \mathrm{~L}$ with $400 \mu \mathrm{m}$ brass electrode. The discharge current, pulse-on time and pulse-off time with three levels were selected as major influencing parameters. The effect on MRR and TWR when $T_{o n}=3,6$ and $9 \mu \mathrm{s}$ are presented in Fig. 6a, b and c, respectively.

From Fig. 6a, it is observed that when $T_{\text {on }}=3$ $\mu \mathrm{s}$, the MRR increases linearly from $0.645 \mathrm{mg} / \mathrm{s}$ to $2.582 \mathrm{mg} / \mathrm{s}$. The rate of increase in MRR varies on the discharge current. The rate of change in MRR is 0.18 $\mathrm{mg} / \mathrm{s}$ in the range of 6 to $9 \mathrm{~A}$, and it is $0.61 \mathrm{mg} / \mathrm{s}$ in the range of 9 to $12 \mathrm{~A}$. In the case of TWR, it is 0.02576 $\mathrm{mg} / \mathrm{s}$ at $6 \mathrm{~A}$ and $0.2551 \mathrm{mg} / \mathrm{s}$ at $12 \mathrm{~A}$, but it is evident that there is a drastic linear increase in TWR between 9 and $12 \mathrm{~A}$.

In the case of $T_{o n}=6 \mu \mathrm{s}, \mathrm{MRR}$ is 0.945 to 2.06539 $\mathrm{mg} / \mathrm{s}$ at 6 to $12 \mathrm{~A}$. It increases linearly at the rate of $0.22975 \mathrm{mg} / \mathrm{s}$ from 6 to $9 \mathrm{~A}$, beyond which, there is no significant increase in MRR. The TWR is $0.0746 \mathrm{mg} / \mathrm{s}$ at $6 \mathrm{~A}$, and it increases linearly at the rate of 0.02424 $\mathrm{mg} / \mathrm{s}$ until $9 \mathrm{~A}$, beyond which a sudden increase is noticed.

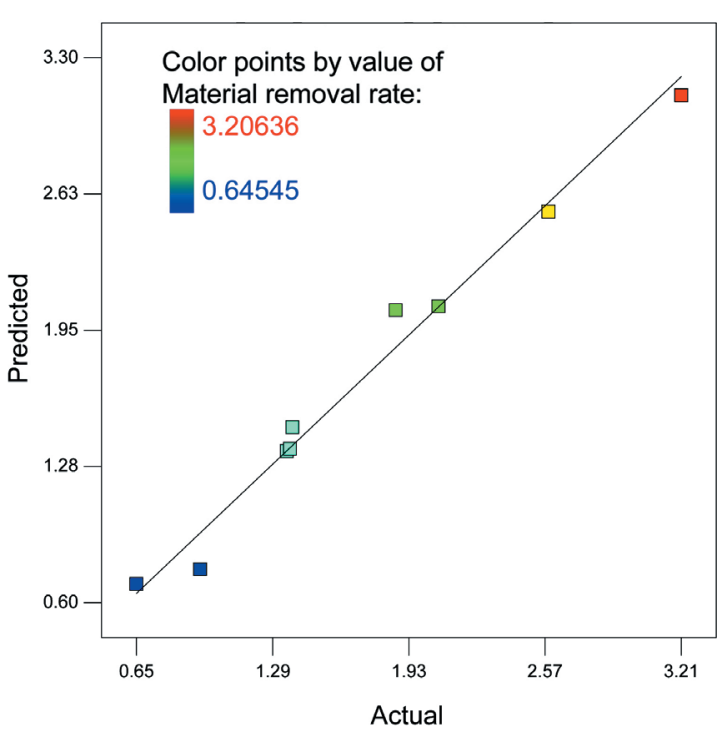

Fig. 4. Linear correlation between actual values and predicted values of MRR

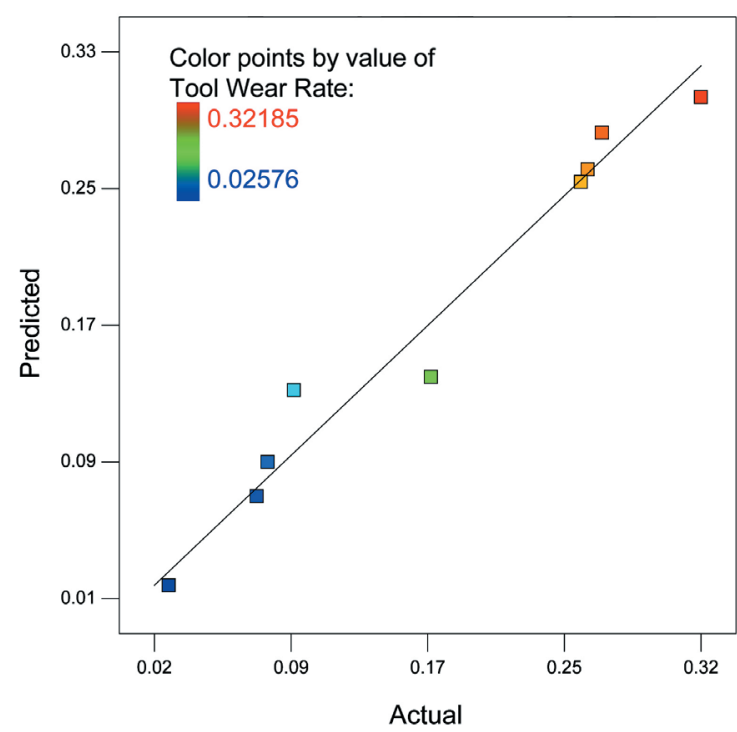

Fig. 5. Linear correlation between actual values and predicted values of TWR

When $T_{\text {on }}=9 \mu \mathrm{s}$, there is no effect of the change in MRR between 6 and $9 \mathrm{~A}$, but it suddenly increases to $3.2 \mathrm{mg} / \mathrm{s}$ at $12 \mathrm{~A}$. In the case of TWR, the linear increase from 0.0807 to $0.2588 \mathrm{mg} / \mathrm{s}$ is noticed from 6 to $9 \mathrm{~A}$, beyond which it is found to be almost constant.

\subsection{Effect of Discharge Current on MRR and TWR with Various Pulse-off Time}

The effect on MRR and TWR with respect to $T_{\text {off }}=3$, 6 and $9 \mu$ s is plotted in Fig. 7a, b and c respectively. 


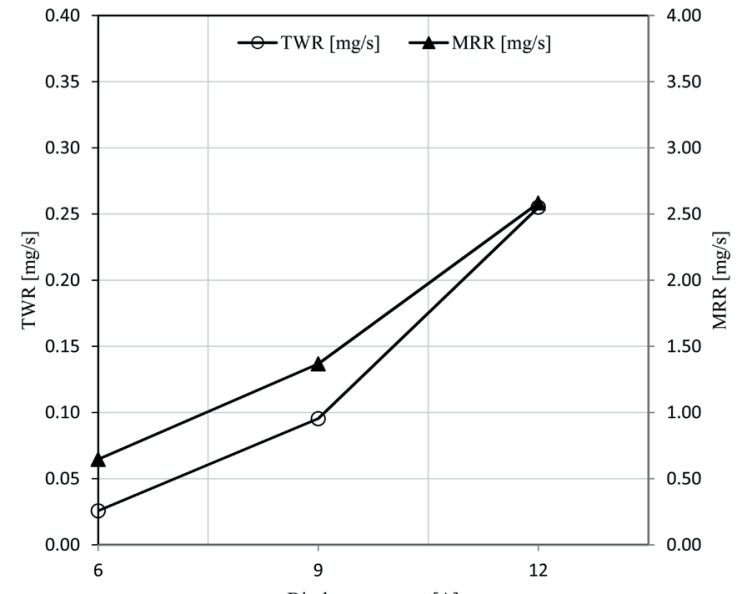

a)

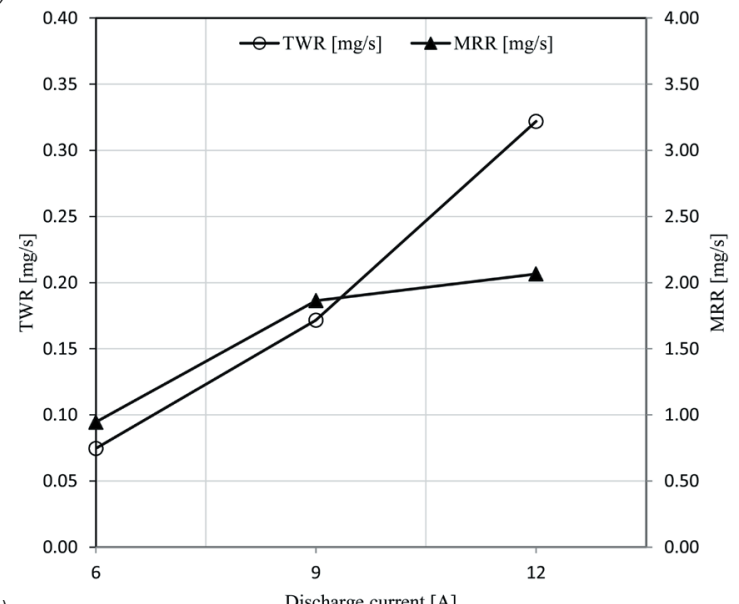

b)

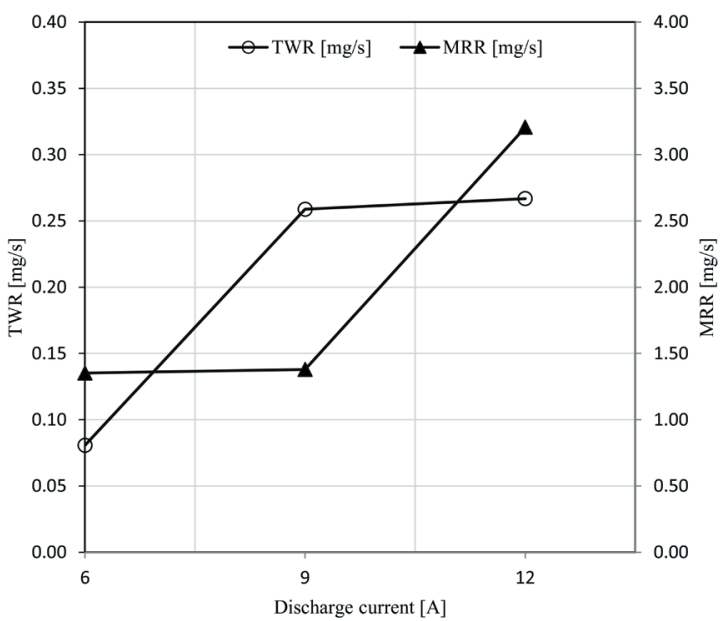

Fig. 6. Effect of discharge on MRR and TWR when; a) $T_{\text {on }}=3 \mu \mathrm{s}$, b) $T_{\text {on }}=6 \mu \mathrm{s}$, and c) $T_{\text {on }}=9 \mu \mathrm{s}$

In the case of $3 \mu \mathrm{s}$, the MRR at $6 \mathrm{~A}$ is 0.6455 $\mathrm{mg} / \mathrm{s}$ and it increases very linearly to $2.0654 \mathrm{mg} / \mathrm{s}$ at $12 \mathrm{~A}$. The TWR is $0.02576 \mathrm{mg} / \mathrm{s}$ at $6 \mathrm{~A}$ and increases to $0.2588 \mathrm{mg} / \mathrm{s}$ at $9 \mathrm{~A}$ and then increases to 0.32185 $\mathrm{mg} / \mathrm{s}$ at $12 \mathrm{~A}$.

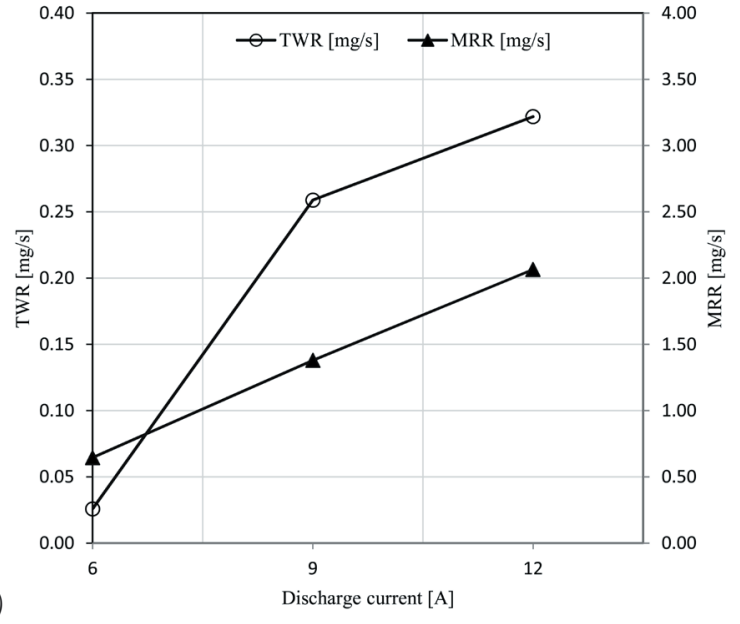

a)

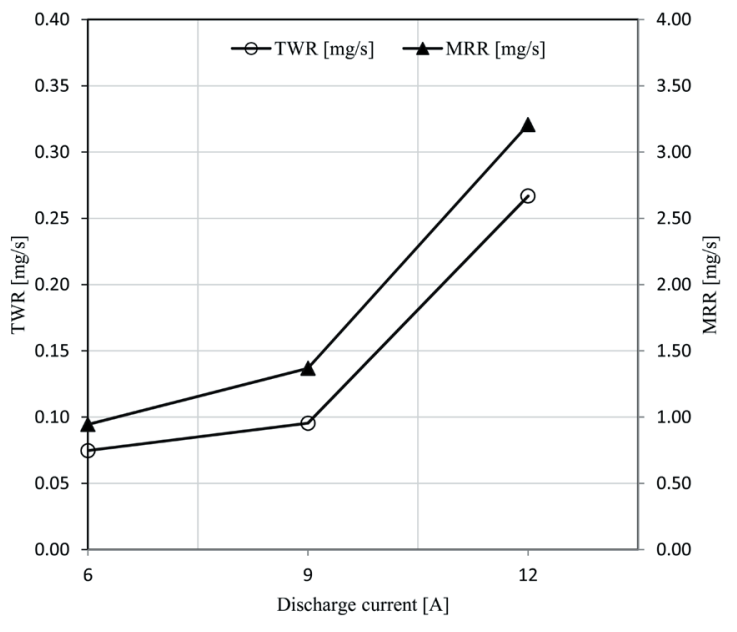

b)

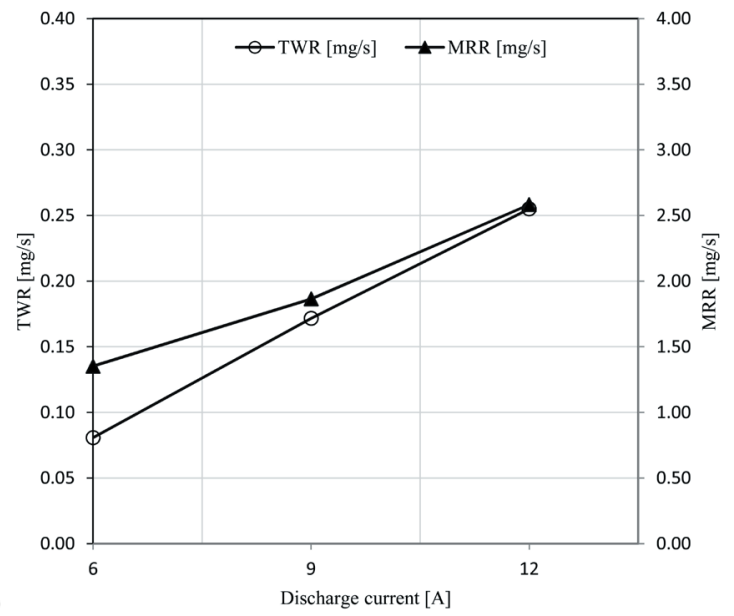

Fig. 7. Effect of discharge on MRR and TWR when;

a) $\left.T_{\text {off }}=3 \mu \mathrm{s}, b\right) T_{\text {off }}=6 \mu \mathrm{s}$, and c) $T_{\text {off }}=9 \mu \mathrm{s}$

In the case of $6 \mu \mathrm{s}$, the MRR and TWR at $6 \mathrm{~A}$ are $0.945 \mathrm{mg} / \mathrm{s}$ and $0.07466 \mathrm{mg} / \mathrm{s}$ respectively. The trend of increase in both MRR and TWR are almost same. A sudden increase is observed from 9 to $12 \mathrm{~A}$. 
In the case of $9 \mu \mathrm{s}$, the MRR is $1.352 \mathrm{mg} / \mathrm{s}$ at 6 $\mathrm{A}, 1.864 \mathrm{mg} / \mathrm{s}$ at $9 \mathrm{~A}$ and $2.5824 \mathrm{mg} / \mathrm{s}$ at $12 \mathrm{~A}$. The TWR is $0.08077 \mathrm{mg} / \mathrm{s}$ at $6 \mathrm{~A}, 0.1716 \mathrm{mg} / \mathrm{s}$ at $9 \mathrm{~A}$ and $0.25506 \mathrm{mg} / \mathrm{s}$ at $12 \mathrm{~A}$.

\section{MULTI-OBJECTIVE OPTIMIZATION USING A GENETIC ALGORITHM}

The optimization seeks to minimize or maximize the value of a function in a given search space. Evolutionary algorithms are popular as robust and effective methods for solving optimization problems. These algorithms apply the principle of survival of the fittest to find the best approximations. A new set of approximations is created at each generation by the process of selecting individual potential solutions (individuals) according to their level of fitness in the problem domain and breeding them together using operators borrowed from natural genetics. This process leads to the evolution of populations of individuals that are better suited to their environment.

A wide range of evolutionary algorithms for multi-objective optimization is available. An NSGA is one of the second generation evolutionary algorithms proposed by Deb et al. [19] and [20]. Many authors have discussed evolutionary algorithms in their research [21] to [23]; the multi-objective problem [24] to [26] is comprehensively dealt with. In recent years, several other algorithms, such as ant colony optimization (MOACO) [27], artificial immune systems [28], and particle swarm optimization (MOPSO) [29] have also been used in multi-objective optimization. These kinds of algorithms have also been applied in manufacturing processes [30] to [32]. These heuristic algorithms [33] to [35] are mainly applied for optimal search. Optimization based on using meta-heuristic algorithms starts with an initial set of independent variables and then evolves to obtain the global minimum/maximum of the objective (fitness) function. The objective function is a mathematical model (function) that assigns a value to each solution in the search space. Starting from an initial solution built with some heuristics, meta-heuristics improve it iteratively until a stopping criterion is met. The NSGA-II considered in this paper is a fast non-dominated sorting approach with computational complexity is introduced, where is the number of objectives and is the population size. It is a steady-state genetic algorithm, which is more suitable for machining applications.

The MATLAB GA multi objective tool box was applied to predict the optimum process parameters. The mathematical models developed using RSM were used in tool box as fitness functions. The objectives are to maximize the MRR minimize the TWR. In order to convert objective for minimization, it is suitably modified. The objective functions are framed as;

Objective $1=1 /$ MRR,

Objective 2 = TWR,

subject to:

$$
6 \leq x_{1} \geq 12, \quad 3 \leq x_{2} \geq 9, \quad 3 \leq x_{3} \geq 9 .
$$

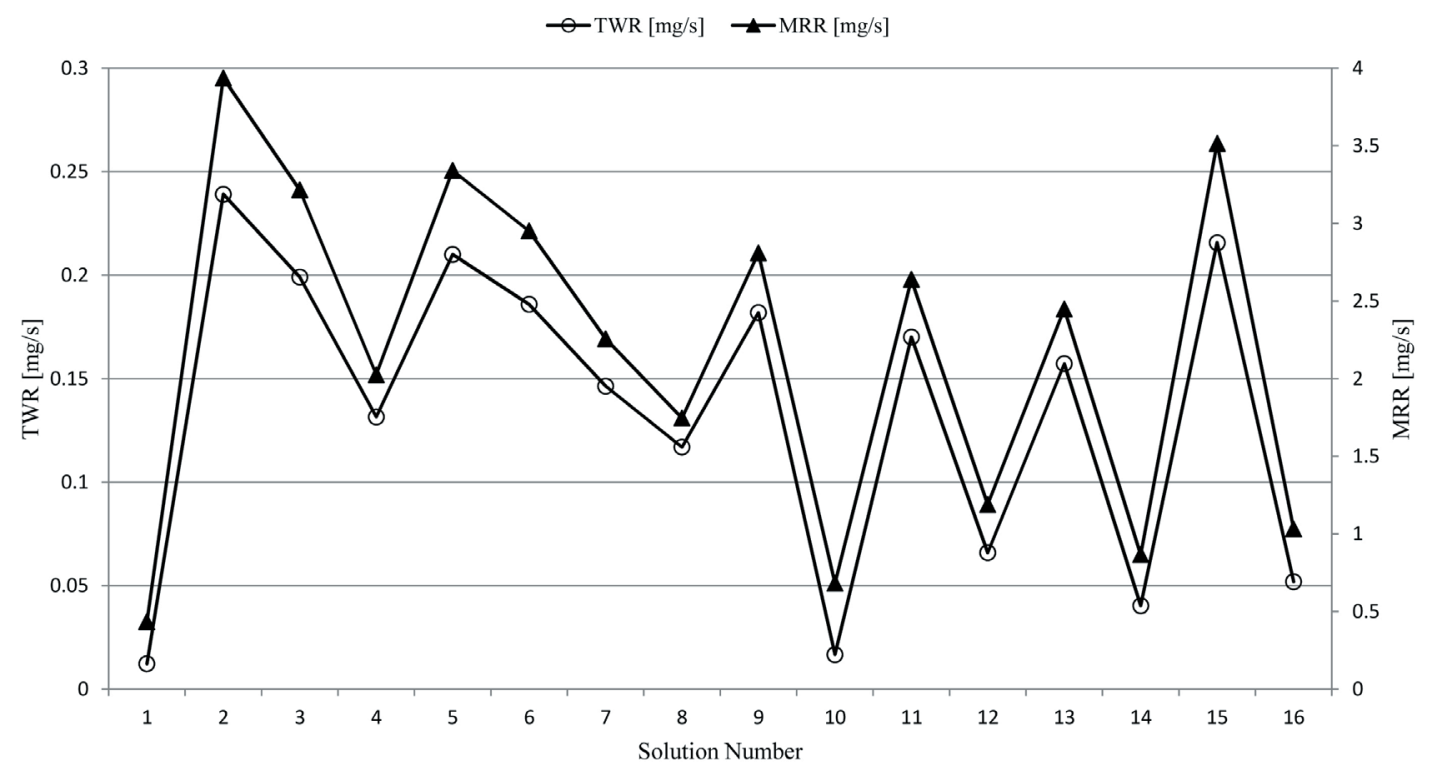

Fig. 8. Obtained optimal solutions from GA 
The GA generally includes three fundamental genetic operations of selection, crossover and mutation. These operations are used to modify the chosen solutions and select the most appropriate offspring to pass on to the succeeding generations. A population size of 45 , a cross-over fraction of 0.8 and a scattered cross-over function were selected from the tool. The tool considered a two-point cross-over function by default. The mutation rate was observed to be 0.01 .

\subsection{Results from the Multi objective GA}

The observed responses corresponding to control parameters are listed in Table 3. The multi-objective GA predicts low MRR of $0.4352 \mathrm{mg} / \mathrm{s}$ and TWR of $0.0122 \mathrm{mg} / \mathrm{s}$ corresponding to $T_{o n}=3.3608 \mu \mathrm{s}$, $T_{\text {off }}=8.6356 \mu \mathrm{s}$ and discharge current is $6.0263 \mathrm{~A}$. The high MRR is observed with TWR $=0.2391 \mathrm{mg} / \mathrm{s}$ at the condition $T_{\text {on }}=8.9999 \mu \mathrm{s}, T_{\text {off }}=8.9185 \mu \mathrm{s}$, and the discharge current is $11.9991 \mathrm{~A}$.

Table 3. Process decision variables corresponding to each of optimal solution point and the predicted responses using GA

\begin{tabular}{ccccc}
\hline \multicolumn{3}{c}{ Control Parameters } & \multicolumn{2}{c}{ Responses } \\
\hline $\begin{array}{c}\text { Pulse-on } \\
\text { time }\left(T_{\text {on }}\right)\end{array}$ & $\begin{array}{c}\text { Pulse-off } \\
\text { time }\left(T_{\text {off }}\right)\end{array}$ & $\begin{array}{c}\text { Discharge } \\
{[\mathrm{A}]}\end{array}$ & $\begin{array}{c}\text { MRR } \\
{[\mathrm{mg} / \mathrm{s}]}\end{array}$ & TWR $[\mathrm{mg} / \mathrm{s}]$ \\
\hline 3.3608 & 8.6356 & 6.0263 & 0.4352 & 0.0122 \\
\hline 8.9999 & 8.9185 & 11.9991 & 3.9366 & 0.2391 \\
\hline 8.8931 & 8.9147 & 10.3863 & 3.2150 & 0.1991 \\
\hline 7.2814 & 8.8935 & 8.3505 & 2.0248 & 0.1315 \\
\hline 8.6525 & 8.8813 & 10.8190 & 3.3404 & 0.2100 \\
\hline 8.7242 & 8.8797 & 9.8730 & 2.9507 & 0.1859 \\
\hline 7.8617 & 8.8742 & 8.6471 & 2.2571 & 0.1464 \\
\hline 8.3824 & 8.6987 & 7.2569 & 1.7457 & 0.1169 \\
\hline 8.1827 & 8.8591 & 9.8165 & 2.8097 & 0.1819 \\
\hline 4.0178 & 8.6923 & 6.4205 & 0.6819 & 0.0167 \\
\hline 8.2307 & 8.8723 & 9.3832 & 2.6393 & 0.1701 \\
\hline 5.4919 & 8.8640 & 7.0884 & 1.1875 & 0.0659 \\
\hline 8.1926 & 8.8996 & 8.9381 & 2.4486 & 0.1572 \\
\hline 3.4702 & 8.7186 & 7.1761 & 0.8655 & 0.0403 \\
\hline 8.9546 & 8.9166 & 11.0506 & 3.5157 & 0.2157 \\
\hline 4.9293 & 8.8463 & 6.9434 & 1.0325 & 0.0519 \\
\hline
\end{tabular}

It is observed that $T_{o n}$ and discharge are to be set low for low MRR and must be set high for high MRR. It is also observed that when MRR increases, TWR also increases correspondingly. However, the objective of this research is to maximize MRR and minimize TWR. Hence, the obtained optimal solutions from GA is presented in Fig. 8.

\subsection{Confirmation Test}

The confirmatory experiments were further conducted for the optimal parameters obtained from the MATLAB multi-objective GA. The error between optimum values from GA and the confirmation test was derived by considering Serial No. 6 from the Table 3, at the condition $T_{o n}=8.7 \mu \mathrm{s}, T_{\text {off }}=8.9 \mu \mathrm{s}$ and discharge $9.87 \mathrm{~A}$, and is shown in Table 4.

Table 4. Error between optimum values from GA and confirmation test value

\begin{tabular}{cccccc}
\hline \multicolumn{2}{c}{$\begin{array}{c}\text { Obtained from GA } \\
{[\mathrm{mg} / \mathrm{s}]}\end{array}$} & \multicolumn{2}{c}{$\begin{array}{c}\text { Confirmation test } \\
\text { value }[\mathrm{mg} / \mathrm{s}]\end{array}$} & \multicolumn{2}{c}{ Error [\%] } \\
\hline MRR & TWR & MRR & TWR & MRR & TWR \\
\hline 2.9506 & 0.1859 & 2.831 & 0.1954 & 4.06 & 5 \\
\hline
\end{tabular}

The average prediction error for MRR is $4.06 \%$, and TWR is $5 \%$. Thus, the GA predicted results are within the acceptable limits, thereby establishing the validity of the method proposed.

\section{CONCLUSION}

A new attempt to optimize the intervening parameters in microEDM of Stainless Steel 316L using a 400 $\mu \mathrm{m}$ brass electrode was done. It was intended to obtain better MRR and TWR simultaneously. The discharge current, pulse-on time and pulse-off time with three levels were considered to be the major intervening parameters in microEDM of SS316L. The mathematical model was derived from RSM, and the result of it was used as a fitness function for multiobjective optimization using GA. The results reveal that the developed mathematical models significantly improve the chosen objectives of obtaining the better MRR and TWR. The multi-objective optimization processes have categorically revealed the interaction effects among the chosen intervening parameters. The optimization model was developed by simultaneously considering the maximization of MRR and minimization of TWR, which is highly useful for real life applications. It is evident from the confirmation results that the developed mathematical model yields the results with a deviation of $5 \%$ from the experimentation.

\section{ACKNOWLEDGEMENT}

We acknowledge the financial assistance provided by All India Council for Technical Education (AICTE), New Delhi under the RPS File no 8023/BOR/RID/ RPS-96/2009-10 and Sona College of Technology. 
We also thank the management of Sona College of Technology for the continuous encouragement and support.

\section{REFERENCES}

[1] Mahendran, S., Devarajan, R., Nagarajan, T., Majdi, A. (2010). A review of microEDM. Proceedings of the International MultiConference of Engineers and Computer Scientists, vol. 2, Hong Kong.

[2] Joshi, S.N., Pande, S.S. (2011). Intelligent process modeling and optimization of die - sinking electric discharge machining. Applied Soft Computing, vol. 11, no. 2, p. 2743-2755, DOI:10.1016/j.asoc.2010.11.005.

[3] Mohamad, A.B., Siddique, A.N., Quadir, G.A., Khan, Z.A., Saini, V.K. (2012). Optimization of EDM parameters using Taguchi method. Proceeding of International Conference on Applications and Design in Mechanical Engineering, Penang.

[4] Rose, P.J. (2005). Taguchi Techniques for Quality Engineering (2nd ed.) Tata McGraw Hill, New Delhi.

[5] Manna, A., Salodkar, S. (2008). Optimization of machining conditions for effective turning of E0300 alloy steel. Journal of Materials Processing Technology, vol. 203, no. 1-3, p.147-153, DOI:10.1016/j. jmatprotec.2007.09.052.

[6] Natarajan, N. Arunachalam, R.M. (2011). Optimization of microEDM with multiple performance characteristics using Taguchi and Grey relational analysis. Journal of Scientific and Industrial Research, vol. 70, no. 7, p 500-505.

[7] Dhanabalan, S., Sivakumar, K., Sathiya Narayanan, C. (2012). Optimization of EDM process parameters with multiple Performance characteristics for Titanium Grades. European Journal of Scientific Research, vol. 68, no. 3, p. 297-305.

[8] Mukherjee, I., Ray, P.K. (2006). A review of optimization techniques in metal cutting processes. Computers \& Industrial Engineering, vol. 50, no. 1-2, p. 15-34, DOI:10.1016/j.cie.2005.10.001.

[9] Chiang, K.-T., Chang, F.-P. (2006). Application of response surface methodology in the parametric optimization of a pin-fin type heat sink. International Communications in Heat and Mass Transfer, vol. 33, no. 7, p. 836-845, DOI:10.1016/j. icheatmasstransfer.2006.04.011.

[10] Rajesh, R., Dev Anand, M. (2012). The optimization of the electro-discharge machining process using response surface methodology and genetic algorithms. Procedia Engineering, International Conference on Modelling, Optimization and Computing, vol. 38, p. 3941-3950, DOI:10.1016/j.proeng.2012.06.451

[11] Karthikeyan, G., Ramkumar, J., Dhamodaran, S., Aravindan, S. (2010). Micro electric discharge milling process performance: an experimental investigation. International Journal of Machine Tools \& Manufacture, vol. 50, no. 8, p. 718-727, DOI:10.1016/j. ijmachtools.2010.04.007.
[12] Kung, K.Y., Horng, J.T., Chiang, K.T. (2009). Material removal rate and electrode wear ratio study on the powder mixed electrical discharge machining of cobaltbonded tungsten carbide. International Journal of Advanced Manufacturing Technology, vol. 40, no. 1-2, p. 95-104, DOI:10.1007/s00170-007-1307-2.

[13] Samtaş, G., Çiçek, A., Kıvak, T., Çay, Y. (2012). Modeling of thrust forces in drilling of AISI 316 stainless steel using artificial neural network and multiple regression analysis. Strojniški vestnik Journal of Mechanical Engineering, vol. 58, no. 7-8, p. 492-498, DOI:10.5545/sv-jme.2011.297.

[14] Saric, T., Simunovic, G., Simunovic, K. (2013). Use of neural networks in prediction and simulation of steel surface roughness. International Journal of Simulation Modelling, vol. 12, no. 4, p. 225-236, DOI:10.2507/ IJSIMM12(4)2.241.

[15] Kao, P.S., Hocheng, H. (2003). Optimization of electrochemical polishing of stainless steel by grey relational analysis. Journal of Materials Processing Technology, vol. 140, no. 1-3, p. 255-259, DOI:10.1016/ S0924-0136(03)00747-7.

[16] Lee, S.S.G., Tam, S.C., Loh, N.H. (1993). Ball burnishing of 316L stainless steel. Journal of Materials Processing Technology, vol. 37, no. 1-4, p. 241-251, DOI:10.1016/0924-0136(93)90094-M.

[17] Bharti, P.S., Maheshwari, S., Sharma, C. (2012). Multiobjective optimization of electric-discharge machining process using controlled elitist NSGA-II. Journal of Mechanical Science and Technology, vol. 26, no. 6, p. 1875-1883, DOI:10.1007/s12206-012-0411-x.

[18] Baraskar, S.S., Banwait, S.S., Laroiya, S.C. (2013). Multi objective optimization of electrical discharge machining process using a hybrid method. Materials and Manufacturing Processes, vol. 28, no. 4, pp. 348354, DOI:10.1080/10426914.2012.700152.

[19] Deb, K., Agrawal, S., Pratap, A. (2000). A fast elitist non-dominated sorting genetic algorithm for multiobjective optimization: NSGA-II. Proceedings of the $6^{\text {th }}$ International Conference on Parallel Problem Solving from Nature, Paris, p. 849-858.

[20] Deb, K., Agrawal, S., Pratap, A., Meyarivan, C. (2002). A fast and elitist multiobjective genetic algorithm: NSGA-II. Evolutionary Computation, vol. 6, no. 2, p. 182-197, DOI:10.1109/4235.996017.

[21] Goldberg, D.E. (1989). Genetic Algorithms in Search, Optimization \& Machine Learning. Addison-Wesley, Indianapolis.

[22] Srinivas, N., Deb, K. (1994). Multiobjective optimization using nondominated sorting in genetic algorithms. Evolutionary Computation, vol. 2, no. 3, p. 221-248, DOI:10.1162/evco.1994.2.3.221.

[23] Horn, J., Nafpliotis, N., Goldberg, D.E. (1994). A niched Pareto genetic algorithm for multiobjective optimization. Proceedings of the 1st IEEE Conference on Evolutionary Computation, Orlando, p. 82-87.

[24] Bentley, P.J., Wakefield, J.P. (1997). Finding acceptable solutions in the Pareto-optimal range using 
multiobjective genetic algorithms. Proceedings of the 2nd On-Line World Conference on Soft Computing in Engineering Design and Manufacturing, p. 231-240.

[25] Zitzler, E., Thiele, L. (1999). Multiobjective evolutionary algorithms: A comparative case study and the strength Pareto approach. IEEE Transactions on Evolutionary Computation, vol. 3, no. 4, p. 257-271, DOI:10.1109/4235.797969.

[26] Deb, K. (1999). Multi-objective genetic algorithms: Problem difficulties and construction of test problem. Journal of Evolutionary Computation, vol. 7, no. 3, p. 205-230, DOI:10.1162/evco.1999.7.3.205.

[27] Garca, C., Cordn, O., Herrera, F. (2004). An empirical analysis of multiple objective ant colony optimization algorithms for the Bi-criteria TSP. ANTS Workshop, p. 61-72.

[28] Cruz-Corts, N., Coello, C.A. (2003). Multiobjective optimization using the clonal selection principle immune system. 9th Electrical Engineering Conference, p. $470-477$.

[29] Durillo, J., Garca, J., Nebro, A., Coello, C., Luna, F., Alba, E. (2009). Multi-objective particle swarm optimizers: An experimental comparison. $5^{\text {th }}$ International Conference on Evolutionary MultiCriterion Optimization, Nantes, p. 495-509.

[30] Ciurana, J., Arias, G., Özel, T. (2009). Neural network modelling and particle swarm optimization (PSO) of process parameters in pulsed laser micromachining of hardened AISI H13 steel. Materials and
Manufacturing Processes, vol. 24, no. 3, p. 358-368, DOI:10.1080/10426910802679568.

[31] Zain, A.M., Haron, H., Sharif, S. (2010). Application of GA to optimize cutting conditions for minimizing surface roughness in end milling machining process. Expert Systems with Applications, vol. 37, no. 6, p. 4650-4659, DOI:10.1016/j.eswa.2009.12.043.

[32] Rao, R.V., Pawar, P.J., Davim, J.P. (2010). Optimisation of process parameters of mechanical type advanced machining process using a simulated annealing algorithm. International Journal of Materials and Product Technology, vol. 37, no. 1-2, p. 83-101, DOI:10.1504/IJMPT.2010.029461.

[33] Samanta, S., Chakraborty, S. (2011). Parametric optimization of some non-traditional machining processes using artificial bee colony algorithm. Engineering Applications of Artificial Intelligence, vol. 24, no. 6, p. 946-957, DOI:10.1016/j. engappai.2011.03.009.

[34] Madić, M., Marković, D., Radovanović, M. (2012). Optimization of surface roughness when turning polyamide using ANN-IHSA approach. International Journal of Engineering \& Technology, vol. 1, no. 4, p. 432-443, DOI:10.14419/ijet.v1i4.378.

[35] Yildiz, A.R. (2013). Cuckoo search algorithm for the selection of optimal machining parameters in milling operations. The International Journal of Advanced Manufacturing Technology, vol. 64, no. 1-4, p. 55-61, DOI: $10.1007 / \mathrm{s} 00170-012-4013-7$. 